\title{
ANALYSIS \\ SPECTRAL SHAPES FROM \\ CALIFORNIA AND \\ CENTRAL UNITED STATES \\ GROUND MOTION
}

\author{
January 24, 1994 \\ Report Prepared by \\ Risk Engineering, Inc. \\ 4155 Darley Avenue, Suite A \\ Boulder, Colorado 80303 \\ under \\ Subcontract No. 1BK-AFB10-80
}

\author{
Prepared for \\ Oak Ridge Y-12 Plant \\ Oak Ridge, Tennessee 37831 \\ manajed by \\ Martin Marietta Energy Systems, inc. \\ for the \\ U. S. DEPARTMENT OF ENERGY \\ under contract DE-AC05-840R21400
}




\section{INTRODUCTION}

The objective of this study is to analyze the spectral shapes from earthquake records with magnitudes and distances comparable to those that dominate seismic hazard at Oak Ridge, in order to provide guidance for the selection of site-specific design-spectrum shapes for use in Oak Ridge. We rely heavily on California records because the number of relevant records from the central and eastern United States (CEUS) is not large enough for drawing statistically significant conclusions. We focus on the 0.5 to $10-\mathrm{Hz}$ frequency range for two reasons: (1) this is the frequency range of most engineering interest, and (2) we avoid the effect of well-known differences in the high-frequency energy content between California and CEUS ground motions.

\section{BACKGROUND: FACTORS THAT AFFECT SPFCTRAL SHAPES}

This section describes the main factors that affect the spectral shapes of earthquake ground motions, using generally accepted concepts and results from engineering seismology.

\section{Magnitude}

Larger earthquakes generally break a larger portion of the earth's crust and have longer durations. As a result, larger earthquakes are more effective at producing lower-frequency ground motions and have a higher proportion of low-frequency energy than smaller earthquakes. Figure 1 shows the effect of magnitude on spectral shapes.

As an illustration, consider the development of a design spectrum for a $1 \mathrm{~Hz}$ structure located in the eastern United States, in a region with maximum magnitude in the range of 6.0 to 6.5 .

If we use a spectral shape based on California earthquakes with magnitudes near 7.0, we implicitly assume that the ratio PSV $(1 \mathrm{~Hz}) / \mathrm{PGA}$ is the same for the earthquakes affecting the site as for the magnitude 7.0 California earthquakes used to construct the spectral shape. In fact, we know from seismology and observation that this ratio is lower for earthquakes that threaten our structures, due to the effects of magnitude. Thus, using a California spectral shape (with its higher PSV [1 Hz] /PGA ratios), together with a PGA value appropriate for the hazard at the site, will lead to overestimation of the hazard for the $1 \mathrm{~Hz}$ structure.

\section{High-Frequency Energy}

Earthquake ground motions at rock sites in the western United States have little energy at frequencies higher than $20 \mathrm{~Hz}$ (Hanks, 1982; Anderson and Hough, 1982). In contrast, a number of ground-motion records obtained at hard rock sites in the central and eastern United States (CEUS) have significant energy at frequencies as high as $50 \mathrm{~Hz}$. This high-frequency energy affects the spectral accelerations at high frequencies $(f>20 \mathrm{~Hz})$ as well as the PGA, but it does not affect spectral accelerations as lower frequencies. These differences are generally explained as the result of less damping in the upper crust (e.g., Hanks, 1982), but alternative interpretations have been proposed (e.g., Papageorgiou, 1988). The shape of the power spectrum at high frequency is often parameterized by the frequency $f_{\max }$ (Hanks, 1982) or the attenuation time kappa (Anderson and Hough, 1984). 
As a result of these differences in high-frequency energy, the high-frequency portion of the responsc spectrum is very different for lliese two types of cirthyuakes, as illustrated in Figure 2.

Considering again the $1 \mathrm{~Hz}$ structure in the eastern United States, we note that earthquakes in the east will have higher PGA and similar $1 \mathrm{~Hz}$ amplitudes (hence, lower PSV[1 Hz]/PGA ratios) than California earthquakes of the same magnitude. Thus, using a California spectral shape (with its higher PSV[1 Hz]/PGA ratios), together with a proper eastern PGA attenuation function, will lead to overestimation of the hazard for the $1 \mathrm{~Hz}$ structure.

Distance also has an effect on high-frequency energy, due to anelastic attenuation (i.e., damping) in the earth's crust. High-frequency waves go through more cycles as they travel a certain distance, so they undergo more damping. As a result, ground motions from distant earthquakes contain a lower proportion of high-frequency energy. This effect becomes important at distances of more than $50 \mathrm{~km}$ and has only a minor effect on seismic hazard.

\section{Site Response}

Site responses may have a dramatic effect on earthquake ground motions. Thus, the presence of soil beneath the site greatly affects the spectra of the ground motions expected at the site. Figure 3 illustrates the effect of site response on spectral shape by comparing the spectra from records obtained at two nearby stations: one on firm soil, the other on rock.

Site characteristics affect ground motions through two basic phenomena: elastic amplification of motions as the waves travel through softer materials and as energy is trapped in the softer layers, and increased energy loss due to damping. Both phenomena are frequency dependent. Both phenomena, particularly damping, are also amplitude-dependent.

Deep-soil sites tend to amplify low-frequency motions (for which amplification effects are dominant) and to dampen high-frequency motions (for which damping effects are dominant). The net effect on peak acceleration is typically small, but the effect on spectral shapes may be dramatic.

Shallow-soil sites have little effect on low-frequency energy and tend to amplify high-frequency energy and PGA (for which elastic resonance effects due to trapped energy are dominant).

More details on the two phenomena described above are contained in McGuire et al. (1988) and EPRI (1993) and references thereof. Other phenomena affecting site response are also discussed in these references.

\section{Use of Spectra Associated with High Fractiles}

A common practice in the development of spectral shapes is to select representative records, scale all records to a common PGA, compute their response spectra, and calculate the spectrum associated with the 84 percentile. That is, at each frequency the calculated spectral acceleration is higher than the spectral accelerations in 84 percent of the selected records. This practice was 
followed in the developınent of the NRC Regulatory Guide 1.60 spectrum (NRC, 1973; see also Blume, Newmark and Kapur, 1973).

As one moves to lower frequencies (i.e., away from peak acceleration), the scatter among the selected spectra increases due to the effects of magnitude, high-frequency energy, and site response discussed earlier, in addition to the inherent randomness in spectral shapes (even for sites with similar characteristics). Because of this high scatter at low frequencies, the 84 percentile spectrum deviates substantially at low frequencies from the median value of these same spectra. This difference is not the result of justified conservatism; rather, it is the result of conservatism combined with a sub-optimal, indirect procedure for the estimation of low-frequency spectral accelerations (i.e., an attenuation function for PGA times a constant factor is a much worse predictor of spectral acceleration than an attenuation function for low-frequency spectral acceleration; hence, the indirect estimate will result in higher scatter). 


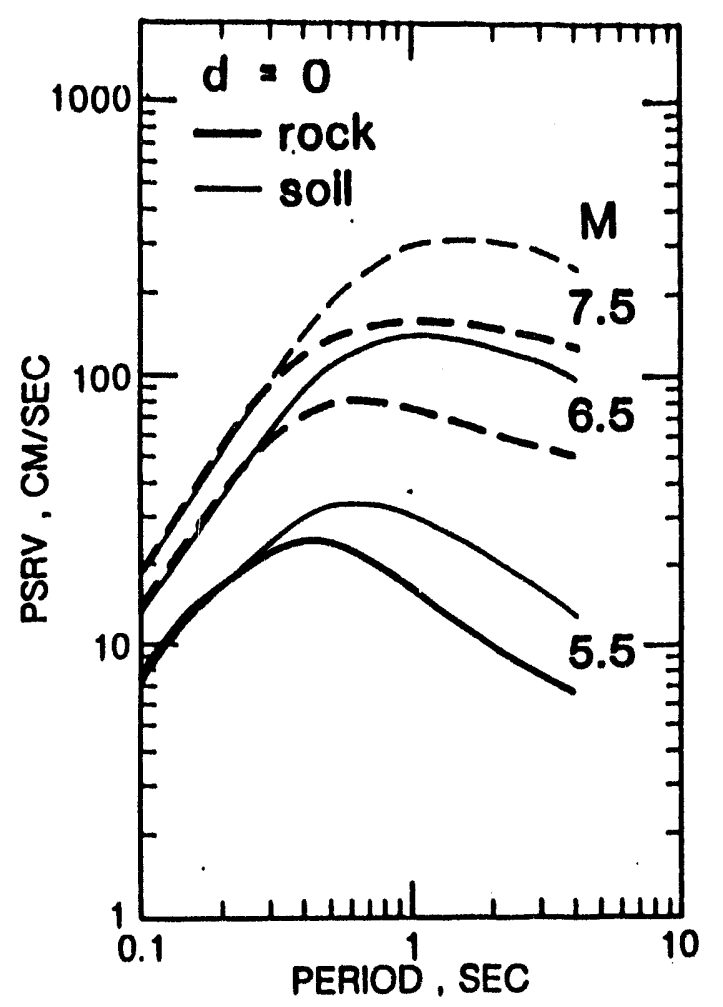

Figure 1: Predicted pseudovelocity response spectra for zero epicentral distance and several values of moment magnitude. Source: Boore and Joyner, 1988. 

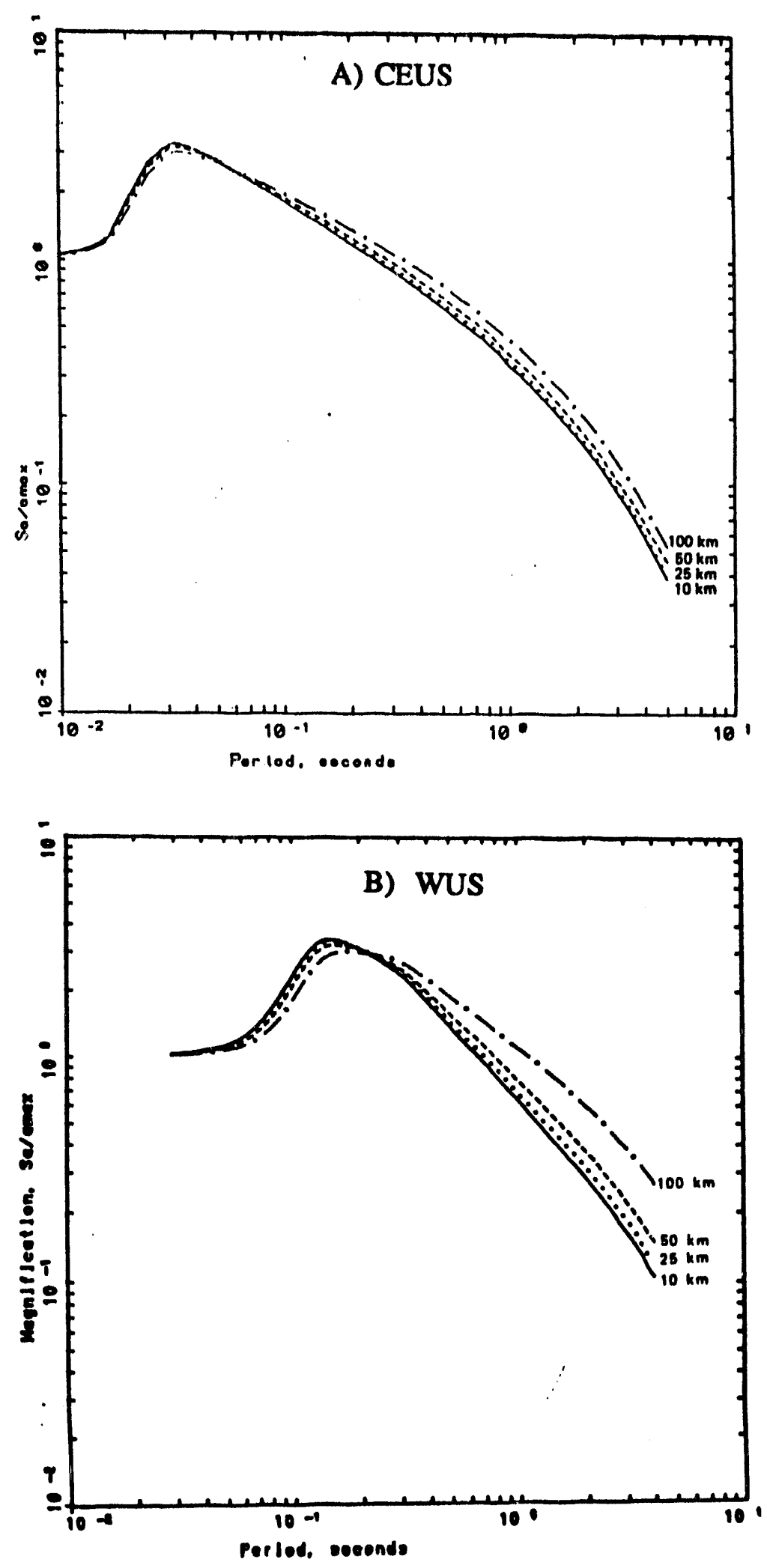

Figure 2: Comparison of spectral shapes for CEUS and western U.S. (WUS) for moment magnitude 6.5. Source: Silva and Green (1989). 


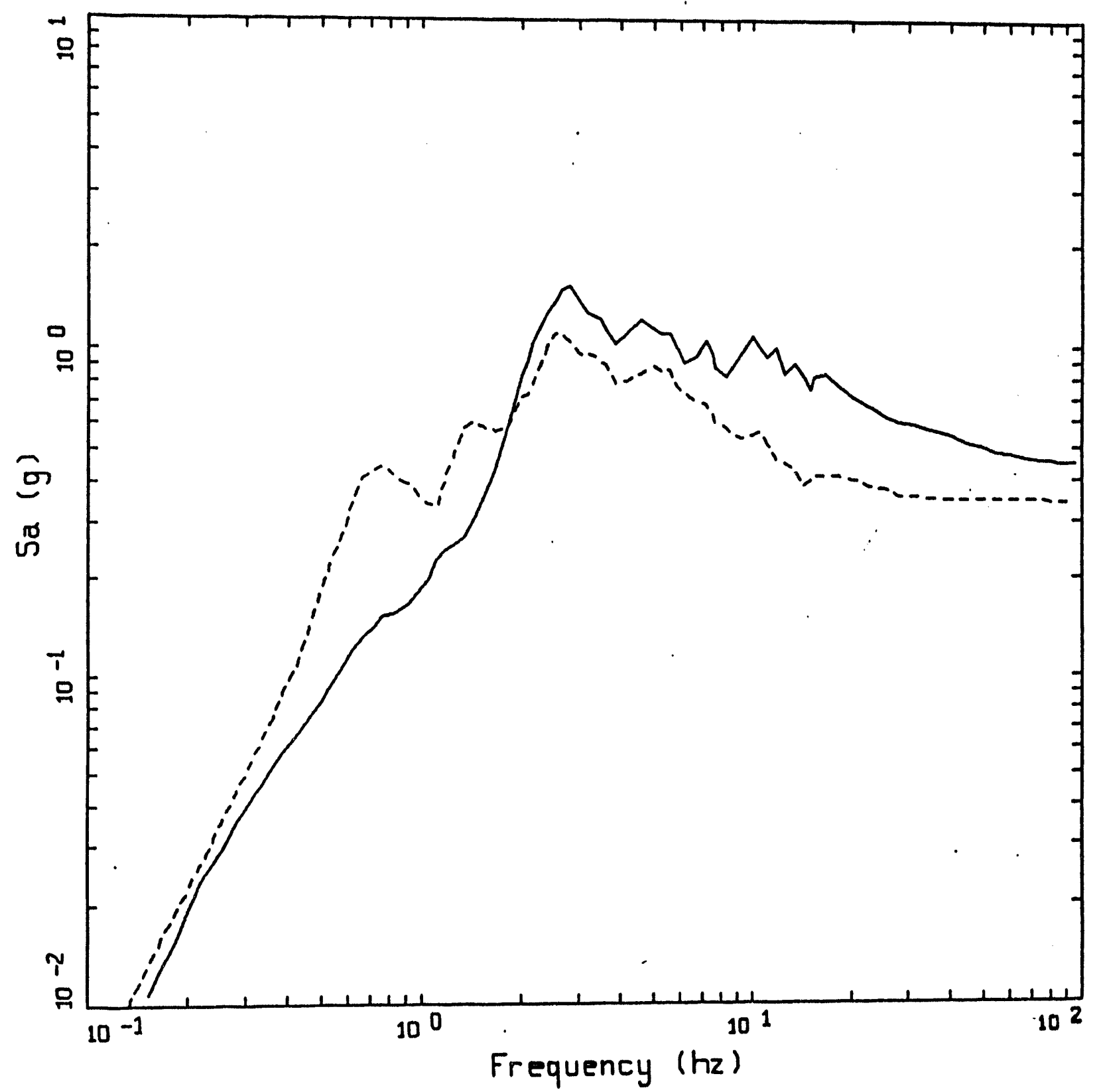

Figure 3: Response spectra (5\% damped) recorded at Gilroy 1 (rock: solid line) and Gilroy 2 (soil: dashed line) during the 1979 Loma Prieta earthquake (the log average of two horizontal components is plotted). Source: EPRI, 1993. 


\section{DOMINANT MAGNITUDES AND DISTANCES FOR OAK RIDGE}

Seismic hazard calculations performed for the Oak Ridge site indicate the following dominant magnitudes and distances for Oak Ridge for $10^{-3}$ annual exceedance probability (Risk Engineering, 1992, 1993):

\begin{tabular}{lcc} 
Ground Motion Measure & $\mathbf{M}\left(\mathbf{m}_{\mathbf{L}}\right)$ & $\mathbf{R}(\mathbf{k m})$ \\
\hline Peak Ground Acceleration (PGA) & 5.6 & 38 \\
2.5-Hz Spectral Velocity & 5.9 & 70 \\
1-Hz Spectral Velocity & 6.35 & 100
\end{tabular}

These magnitudes and distances were computed using the EPRI methodology and seismological interpretations and considering the normalized contributions of various magnitudes and distances to the mean hazard.

These results indicate that seismic hazard at Oak Ridge is due mainly to earthquakes with intermediate magnitudes, even for low structural frequencies.

\section{SELECTION OF RECORDS FOR THIS STUDY}

Based on the dominant magnitudes and distances for PGA and for 1- $\mathrm{Hz}$ spectral velocity, we selected ground-motion records from rock sites in California, for earthquakes in the following magnitude-distance intervals:

a. events that dominate PGA: $m_{L_{g}} 5.25$ to 5.75 (moment magnitude $M 4.8$ to 5.4 ) at 20 to $60 \mathrm{~km}$;

b. events that dominate $1-\mathrm{Hz}$ PSV: $\mathrm{m}_{\mathrm{L}_{\mathrm{g}}} 6.0$ to 6.5 (moment magnitude $\mathrm{M} 5.6$ to 6.3 at 70 $130 \mathrm{~km}$.

The conversion from $\mathrm{m}_{\mathrm{Lg}}$ to moment magnitude was performed using the relationship by Boore and Atkinson (1987)

$$
\mathrm{M}=2.715-0.277 \mathrm{~m}_{\mathrm{L}_{\mathrm{g}}}+0.127 \mathrm{~m}_{\mathrm{L}_{\mathrm{g}}}{ }^{2}
$$

(Figure 4) which is nearly identical to that obtained by Toro et al. (1988).

These magnitude-distance intervals, particularly the second, had to be widened in order to obtain approximately 30 horizontal records (i.e., 15 event-site pairs) in each magnitude-distance category. The final magnitude-distance intervals were M 4.8 to 5.4 at 9 to $60 \mathrm{~km}$ and $\mathbf{M} 5.5$ to 6.5 at 15 to $180 \mathrm{~km}$. There were more than 30 records in the first magnitude-distance interval, 
many of them came from the same event or aftershock sequence. Some of those records were removed from considerition, prior to examining their spectral shapes, in order to obtain a more representative data set. The selected records are listed in Tables 1 and 2. All data were selected from an extensive California strong-motion dataset under development for EPRI (W. Silva, personal communication, 1993). This dataset is particularly rich, relative to other datasets, in the magnitude intervals of interest to this study. 
TABLE 1. RECORDS REPRESENTATIVE OF EVENTS THAT DOMINATE PGA

\begin{tabular}{|c|c|c|c|c|c|c|}
\hline Earthquake & Year & $\begin{array}{l}\text { Date } \\
\text { (mmyy) }\end{array}$ & Time & $\begin{array}{l}\text { Moment } \\
\text { Magnitude } \\
\text { (M) }\end{array}$ & Station & $\begin{array}{l}\text { Dist. } \\
\text { (km) }\end{array}$ \\
\hline San Francisco & 1957 & 0322 & 1944 & 5.3 & Golden Gate Park & 9.5 \\
\hline Lytle Creek & 1974 & 1128 & 2301 & 5.2 & Cedar Springs & 20.6 \\
\hline Lytle Creek & 1974 & 1128 & 2301 & 5.2 & Devis's Canyon & 21.9 \\
\hline Lytle Creek & 1970 & 0912 & 1430 & 5.3 & Santa Anita Dam & 45.9 \\
\hline Hollister & 1974 & 1128 & 2301 & 5.2 & Gilroy Array "1 & 12.3 \\
\hline Northern Calif & 1975 & 0607 & 0846 & 5.2 & Cape Mendocino, Petrolia & 28.9 \\
\hline Northern Calif & 1975 & 0607 & 0846 & 5.2 & Shelter Cove, Sta A & 59.2 \\
\hline Coalinga & 1983 & 0509 & 0249 & 5.1 & Anticline Ridge Free-field & 12.6 \\
\hline Coalinga & 1983 & 0509 & 0249 & 5.1 & Bumett Construction & 12.7 \\
\hline Coalinga & 1983 & 0509 & 0249 & 5.1 & Sulphur Baths (temp) & 12.6 \\
\hline Codlinge & 1983 & 0509 & 0249 & 5.1 & Burnett Construction & 12.7 \\
\hline Coalinga & 1983 & 0509 & 0249 & 5.1 & Skunk Hollow & 12.4 \\
\hline Coalinga & 1983 & 0611 & 0309 & 5.3 & Sulphur Baths (temp) & 9.7 \\
\hline Coalinga & 1983 & 0709 & 0740 & 5.2 & Sulphur Baths (temp) & 17 \\
\hline Coalinga & 1983 & 0709 & 0740 & 5.2 & Oil Fields Fire Station & 10 \\
\hline Coalinga & 1983 & 0709 & 0740 & 5.2 & Skunk Hollow & 12.6 \\
\hline Coalinga & 1983 & 0709 & 0740 & 5.2 & Transmitter Hill & 10.4 \\
\hline Coalinga & 1983 & 0722 & 0343 & 4.9 & Sulphur Baths (temp) & 13.7 \\
\hline Coalinga & 1983 & 0725 & 2231 & 5.2 & Sulphur Baths (temp) & 14.7 \\
\hline Coalinga & 1983 & 0909 & 0916 & 5.3 & Sulphur Baths (temp) & 18.4 \\
\hline
\end{tabular}


Table 2. RECORDS REPRESENTATIVE OF EVENTS THAT DOMINATE 1-Hz PSV

\begin{tabular}{lccclll} 
Earthquake & Year & $\begin{array}{c}\text { Date } \\
\text { (mmyy) }\end{array}$ & $\begin{array}{l}\text { Time } \\
\text { Mnza }\end{array}$ & $\begin{array}{l}\text { Moment } \\
\text { Magnitude } \\
(\mathrm{M})\end{array}$ & Station & $\begin{array}{l}\text { Dist. } \\
(\mathrm{km})\end{array}$ \\
\hline Mammoth Lakes & 1980 & 0225 & 1047 & 5.5 & Borrego Air Ranch & 40.6 \\
Mammoth Lakes & 1980 & 0525 & 1944 & 6.0 & Long Valley Dam (U.L.A) & 19.7 \\
Mammoth Lakes & 1980 & 0525 & 1944 & 6.0 & Long Valley Dam (Down) & 19.7 \\
Westmorland & 1981 & 0426 & 1944 & 6.0 & Long Valley Dam (L.A.) & 19.7 \\
Coalinga & 1983 & 0722 & 0239 & 5.9 & Sulphur Baths (temp) & 15.3 \\
N. Palm Springs & 1986 & 0708 & 0920 & 6.0 & Anza - Red Mountain & 45.6 \\
N. Palm Springs & 1986 & 0708 & 0920 & 6.0 & Santa Rosa Mountain & 43.8 \\
N. Palm Springs & 1986 & 0708 & 0920 & 6.0 & Anza - Tule Canyon & 55.4 \\
N. Palm Springs & 1986 & 0708 & 0920 & 6.0 & Lake Mathews Dike Toe & 73.7 \\
N. Palm Springs & 1986 & 0708 & 0920 & 6.0 & Murrieta Hot Springs & 63.3 \\
N. Palm Springs & 1986 & 0708 & 0920 & 6.0 & Winchester Bergman Ran & 57.6 \\
N. Palm Springs & 1986 & 0708 & 0920 & 6.0 & Silent Valley - Poppet F & 25.8 \\
Whittier Narrows & 1987 & 1001 & 1442 & 6.0 & Carbon Canycn Dam (L.Ab.) & 26.8 \\
Whittier Narrows & 1987 & 1001 & 1442 & 6.0 & Mt Wilson - CrT Seis Sta & 21.2 \\
\hline & & & & & & \\
\hline
\end{tabular}




\section{CALCULATIONS AND COMPARISONS IN THE 0.5 TO 10-Hz RANGE}

We calculate response spectra (for 5\% damping) for calch record and thein compute statistics on log-amplitudes and $\log$ [amplitude ratios] for each group of records. Figures 5 and 6 show the ratio PSV(f)/PGA (in units of $\mathrm{cm} / \mathrm{sec} / \mathrm{g}$ ). Figures 7 through 10 show the dimensionless ratios $\operatorname{PSV}(\mathrm{f}) / \mathrm{PSV}(10 \mathrm{~Hz})$ and $\mathrm{PSV}(\mathrm{f}) / \mathrm{PSV}(2.5 \mathrm{~Hz})$.

Focusing on Figures 5 and 6, we note that the median spectra peak at approximately 5 and $2 \mathrm{~Hz}$, respectively. The corresponding mean+sigma spectra (which are approximately eyual to 84 percentile spectra) peak at slightly lower frequencies. This is consistent with the peaks observed in records from earthquakes in CEUS (Figures 5-13 and 5-14 of Risk Engineering, 1992). Figures 7 through 10 show similar results for their median shapes. These twc sets of observations indicate that the spectra from the earthquakes that dominate the hazard at Oak Ridge are expected to peak in the range of 2 to $5 \mathrm{~Hz}$.

Comparing Figures 5 and 6, we observe the effect of magnitude on spectral shape: the smallermagnitude earthquakes contain a lower proportion of low-frequency energy and have narrower spectra. The same effects are observed in Figures 7 through 10.

Continuing on the issue of spectral shapes, Figures 11 and 12 compare the observed spectral shapes to three spectra derived as part of the Oak Ridge seismic hazard study (Risk Engineering, 1992) and follow-up work by Martin Marietta Energy Systems. These spectra are as follows:

1. The median uniform-hazard spectrum for $10^{-3}$ annual exceedance probability obtained directly as part of conventional seismic-hazard calculations (combining EPRI and LLNL results, including LLNL ground-motion expert 5). This spectrum is lower than the other two because it is associated with median, as opposed to mean hazard.

2. The pseudo-mean spectrum developed for $10^{-3}$ annual exceedance probability from the EPRI and LLNL seismic hazard results by following the Department of Energy Interim Position on the use of EPRI and LLNL resuits (Kimball, 1992).

3. The design spectrum for $10^{-3}$ annual exceedance probability develnped by Martin Marietta Energy Systems.

For these comparisons, the spectral shapes calculated earlier have been scaled so as to coincide with the Interim-Position spectra at $10 \mathrm{~Hz}$ (for the magnitudes that dominate PGA) and at 2.5 $\mathrm{Hz}$ (for the magnitudes that dominate $2.5 \mathrm{~Hz}$ PSV).

Figure 11 shows that the spectra from earthquakes that dominate PGA (they also dominate 10-Hz PSV) are substantially narrower than the spectra obtained from the seismic hazard results. The slope between 5 and $10 \mathrm{~Hz}$ is higher for the California records than for the three spectra derived above. This is probably due to the East-West differences in high-frequency energy, which are already apparent at $10 \mathrm{~Hz}$. As a result of this higher slope, the spectra from the California records is somewhat higher than the Interim Guidelines spectrum at frequencies near $5 \mathrm{~Hz}$, when both spectra are made to coincide at $10 \mathrm{~Hz}$. 
Figure 12 shows consistency between observed and calculated spectral shapes over the range of 1 10 10 11z. Outside this range, the observed spectra are narrower than the calculated spectra.

So far, we have presented relative comparisons, focusing on spectral shapes rather than absolute amplitudes, and we have shown that the spectral shapes used in the Oak Ridge design spectrum and other calculated spectra are consistent (if not conservative) in relation to observations from relevant magnitudes and distances. Figures 13 and 14 will show comparisons that consider amplitudes, as well as shapes. In Figure 13, the observed amplitudes from each record in the first category (earthquakes that dominate the PGA hazard) have been scaled to $\mathbf{M} 5.1$ and 38 km distance using the Boore et al. (1993) attenuation equation for PGA in California. The logarithmic mean and mean $\sigma$ are then computed from the scaled observations. The resulting spectra are compared to the spectral shape predicted by the Toro et al. (1988) CEUS attenuation functions for the corresponding $\mathrm{m}_{\mathrm{Lg}}$ and the same distance. There is very close agreement for all frequencies below $10 \mathrm{~Hz}$. The differences above $10 \mathrm{~Hz}$ are the result of well understood differences in high-frequency energy between California and CEUS.

A similar procedure is followed in Figure 14 for records in the second category (earthquakes that dominate the $1-\mathrm{Hz}$ hazard), this time scaling to $\mathbf{M} 6.1$ and $100 \mathrm{~km}$ using the Boore et al. (1993) attenuation equation for $1-\mathrm{Hz}$ PSV in California. There is very close agreement in the 2 to $10-\mathrm{Hz}$ range and, as expected, the CEUS attenuation functions are higher above $10 \mathrm{~Hz}$. At frequencies below $2 \mathrm{~Hz}$, the CEUS attenuation functions over-predict the amplitudes, suggesting that the attenuation functions are conservative for intermediate to high magnitudes and low frequencies. Atkinson and Boore (1993) have reached this conclusion using a larger data set. There is a mounting body of evidence that suggests that attenuation functions based on point-source stochastic ground-motion models (such as Toro et al., 1988, or EPRI, 1993) over-predict low frequency ground motions for intermediate to high magnitudes.

The results presented in Figures 5 through 12 indicate that the spectral shapes derived for Oak Ridge using results from the seismic hazard results are consistent, if not conservative, with the observed shapes from relevant California records, for frequencies below $10 \mathrm{~Hz}$. Figures 13 and 14 show that CEUS attenuation equations of the type used in the seismic hazard calculations properly predict the absolute amplitudes in the same frequency range and appear to over-predict low frequencies for intermediate magnitudes. These two results justify the use of any of these derived spectral shapes, anchored at frequencies near $2.5 \mathrm{~Hz}$, for deriving design spectra.

\section{COMPARISONS OF LOW FREQUENCY TO HIGH FREQUENCY: CALIFORNIA vs. CEUS}

It is generally accepted that ground motions from rock recordings of CEUS earthquakes have more high-frequency energy than their counterparts in California. This has been attributed to the presence of more competent rock in CEUS than in California.

The additional high-frequency energy of CEUS earthquakes generates higher PGA and higher PSV above $10 \mathrm{~Hz}$ than California earthquakes of comparable magnitudes and distances. This is 
generally accepted and is easily observed by comparing attenuation functions for CEUS and California (after allowing for differences in magnitude scales).

This additional high-frequency energy has no effect on PSV values near $1 \mathrm{~Hz}$ or on peak ground velocity (PGV). This is easily shown using random-vibration theory or time-domain integration.

As a result, CEUS ground motions have spectral shapes different from California ground motions with the same magnitudes and distances, when looking at a wide frequency range. This is in contrast to the comparisons presented earlier, which focused on the narrower 1 to $10-\mathrm{Hz}$ range.

One common measure of the ratio of low frequency to high frequency is the PGV/PGA (typically referred to as the V/A ratio). The logarithmic average of the V/A ratios for the two sets of California records in Tables 1 and 2 is 38 (equal for both categories; for a total of 58 records); the corresponding logarithmic standard deviation is 0.4 . Similar calculations for the CEUS records in Table 5.4 of the Oak Ridge Seismic Hazard study (Risk Engineering, 1982) yield logarithmic averages of 29 for events near magnitude 5.2 (12 records) and 25 for events near magnitude 6 (10 records); the corresponding standard deviation is also 0.4 .

These V/A ratios are compared in Table 3 to the ratios predicted by CEUS and California attenuation functions and to the ratio implicit in some design spectra.

TABLE 3. COMPARISON OF V/A RATIOS

\begin{tabular}{lcc} 
Source & $\begin{array}{c}\mathrm{m}_{\mathrm{Lg}} 5.6 \\
(\mathrm{M} 5.1)\end{array}$ & $\begin{array}{c}\mathrm{m}_{\mathrm{Lg}} 6.35 \\
(\mathbf{M} 6.0) \\
\text { at } 38 \mathrm{~km}\end{array}$ \\
\hline $\begin{array}{l}\text { CEUS Records used in } \\
\text { Risk Engineering (1992) }\end{array}$ & 29 & 25 \\
\hline California Records, this study & 38 & 38 \\
\hline $\begin{array}{l}\text { Atkinson and Boore (1990) attenuation equations for } \\
\text { CEUS }\end{array}$ & 22 & 44 \\
$\begin{array}{l}\text { Atkinson and Boore (1993) attenuation equations for } \\
\text { CEUS }\end{array}$ & 14 & 23 \\
Toro et al. (1988) attenuation equations for CEUS & 18 & 37 \\
\hline Boore and Joyner (1988) attenuation equations for WUS & 27 & 47 \\
\hline $\begin{array}{l}\text { Nemark-Hall (1982) design spectrum (Fig 5) } \\
\text { Newmark, Blume and Kapur (1973) }\end{array}$ & N/A & 132 \\
\hline
\end{tabular}


The V/A ratios from records and from attenuation functions show that there is a significant difference in V/A ratios between CliUS and California. liven if one allows for the small number of CEUS events available for analyses of this type, it is unlikely that the observed differences in V/A ratios are due to chance. These differences are a consistent manifestation of differences in spectral shape.

These ratios also indicate the tendency of V/A to increase with magnitude. The CEUS data in Risk Engineering (1992) do not exhibit this tendency because of the Saguenay earthquake and its unusual frequency content, but it is reasonable to conclude that this tendency applies also to CEUS.

The most striking result from Table 3 is that the V/A ratios implied in standard spectral shapes are much higher than the observed and predicted V/A, ratios for the magnitudes and distances that dominate seismic hazard at Oak Ridge. This is true even for the California data and attenuation functions.

As a result of these differences, use of standard spectral shapes based on California ground motions (which imply high V/A ratios) anchored to PGA values that are appropriate for CEUS, results in spectra that overestimate the hazard for low-frequency structures. The fact that a number of the records represented in standard spectral shapes were obtained at deep-soil sites and from larger earthquakes, makes this situation worse. This conclusion is valid for sites like Oak Ridge that are on rock and are not exposed to seismic sources capable of large-magnitude earthquakes.

\section{CONCLUSIONS}

The comparisons presented here serve to reinforce several well known facts about ground motions at typical rock sites in CEUS, as follows:

1. For a given magnitude and distance, the ground motions in the 1 to $10-\mathrm{Hz}$ frequency range at rock sites in CEUS and California are approximately equal and are properly represented by uniform-hazard spectra and by the CEUS attenuation functions in current use.

2. Because CEUS ground motions are higher than California ground motions at high frequencies and comparable to California ground motions at low frequencies, CEUS ground motions have different spectral shapes and lower V/A ratios than California ground motions. As a result, use of a California-based spectral shape anchored to a CEUS design, PGA would lead to conservatism at low frequencies.

3. The V/A ratios implied in typical design spectral shapes are much higher than the observed or predicted V/A ratios for the magnitude-distance interval that dominates seismic hazard at Oak Ridge. Thus, use of a standard spectral shape anchored to the Oak Ridge design PGA would grossly overestimate spectral amplitedes at frequencies near 1 $\mathrm{Hz}$. 


\section{REFERENCES}

1. J.G. Anderson, and S.E. Hough. "A Model for the Shape of the Fourier Amplitude Spectrum of Acceleration at High Frequencies." BSSA, Vol 74, 1984, pp. 1969-1993.

2. G.M. Atkinson, and D.M. Boore. "Ground Motion Relations for Eastern North America." Manuscript submitted to the Bulletin of the Seismological Society of America, July, 1993.

3. J.A. Blume, N.M. Newmark, and K.K. Kapur. "Seismic Design Spectra for Nuclear Power Plants." Journal of the Power Division, ASCE, Vol 99, No P02, November, 1973.

4. D.M. Boore and G.M. Atkinson. "Stochastic Prediction of Ground Motion and Spectral REsponse Parameters at Hard-Rock Sites in Eastern North America." Bulletin of the Seismological Society of America, 77(2):440-467, 1987.

5. D.M. Boore, W.B. Joyner, and T.E. Fomal. "Estimation of Response Spectra and Peak Accelerations from Western North America Earthquakes: An Interim Report." Open File Report 93-509, U.S. Geological Survey, 1993.

6. D.M. Boore, and W.B. Joyner. "Measurement, Characterization of Strong Ground Motion." Recent Advances in Ground Motion Evaluation, Geotechnical Special Publication No. 20, American Society of Civil Engineers, 1988.

7. "Guidelines for Determining Design Basis Ground Motion." Electric Power Research Institute, Technical Report TR102293, November, 1993.

8. T.C. Hanks. " $f_{\max } " B S S A$, Vol 72, 1982, pp. 1867-1879.

9. J. Kimball. "Use of LLNL and EPRI Probabilistic Seismic Hazard Curves: Interim Position." Attachment to Memorandum of W.H. Young to Program Secretarial Officers, dated March 19, 1992. U.S. Department of Energy, 1992.

10. "Regulatory Guide 1.60: Design Response Spectra for Seismic Design of Nuclear Power Plants." Nuclear Regulatory Commission, 1973.

11. A.S. Papageorgiou. "Earthquake Source Spectra - A Comparison Between Western and Eastern U.S. Earthquakes." In Proceedings: Workshop on Estimation of Ground Motion in the Eastern United States, EPRI NP-5875, 1988.

12. "Seismic Hazard Evaluation for the Department of Energy Oak Ridge Reservations, Oak Ridge, Tennessee." Report to Martin Marietta Energy Systems, Risk Engineering, Inc., 1992. 
13. W.J. Silva, and R.K. Green. "Magnitude and Distance Scaling of Response Spectral Shapes for Rock Sites with Application to North American "lectonic Environments." Earthquake Spectra, 5(4):591-624, 1989.

14. G.R. Toro, R.K. McGuire, and W.J. Silva. "Engineering Model of Earthquake Ground Motion for Eastem North America." Electric Power Research Institute, Technical Report NP-6074, 1988. 


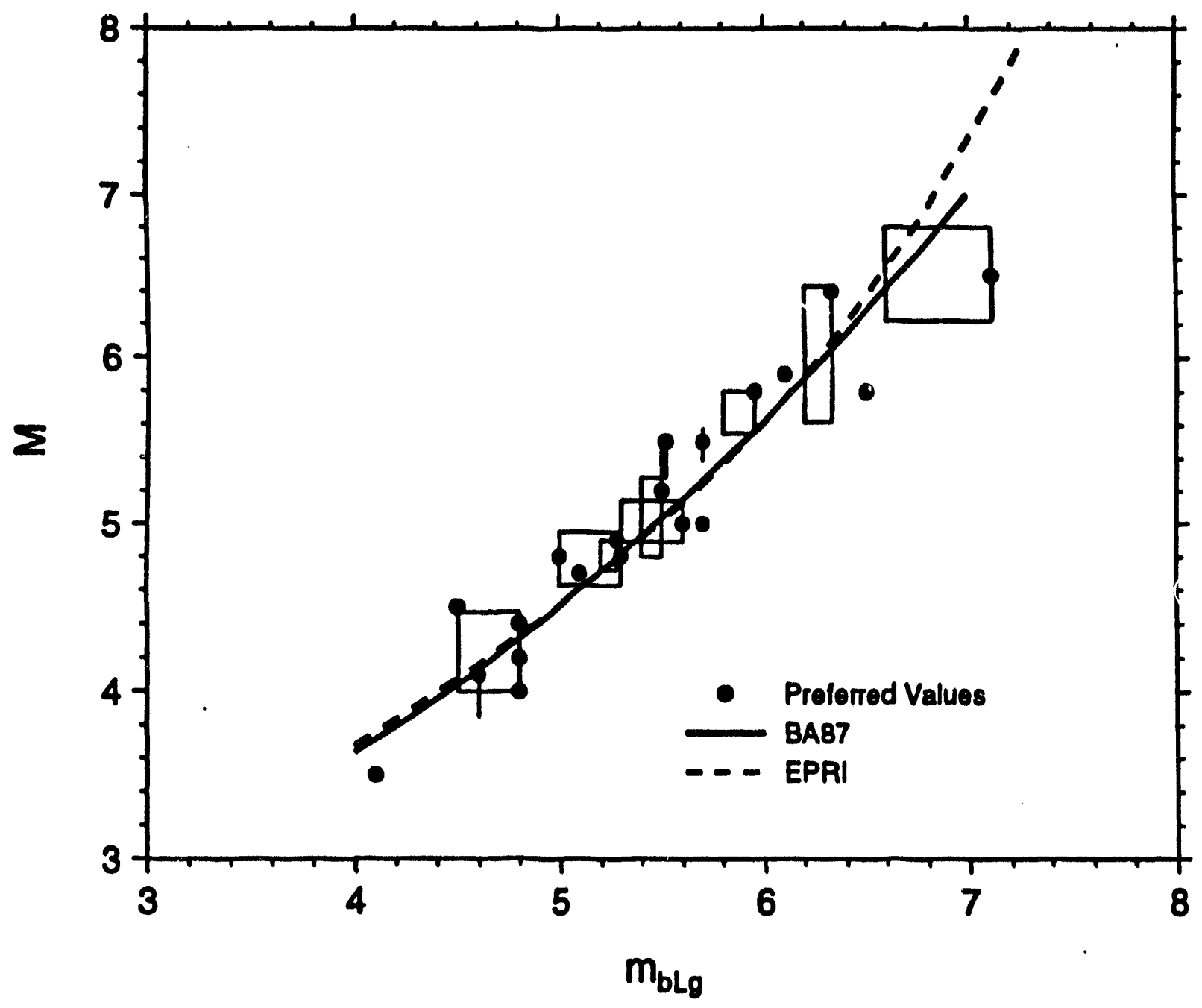

Figure 4: Relationship between seismic moment $M$ and $m_{L_{g}}$. The curves labeled BA87 and EPRI are from Boore and Atkinson (1987) and Toro et al. (1988). The rectangles and dots represent data from Boore and Atkinson (1987). Source: Boore et al. (1993). 


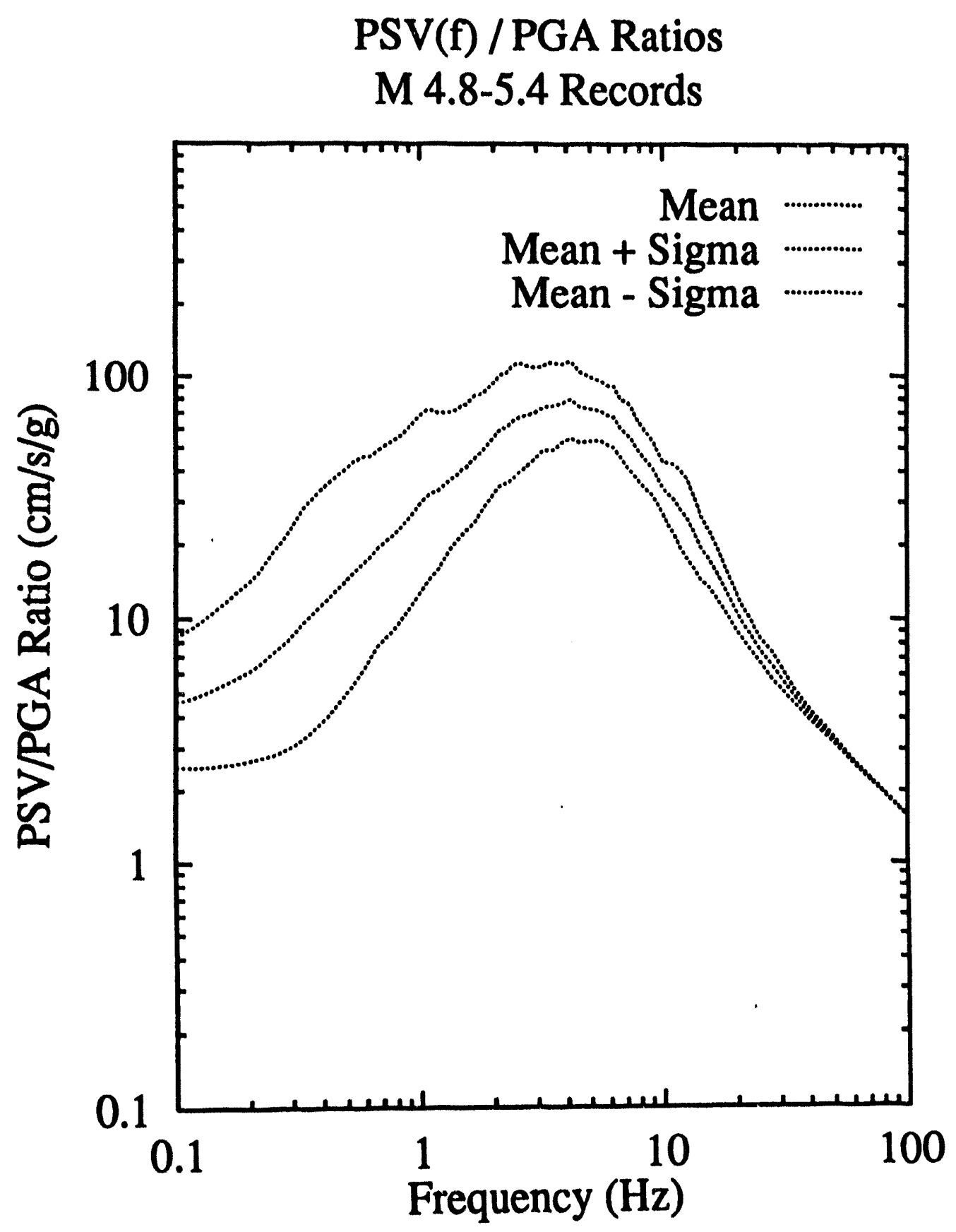

Figure 5 


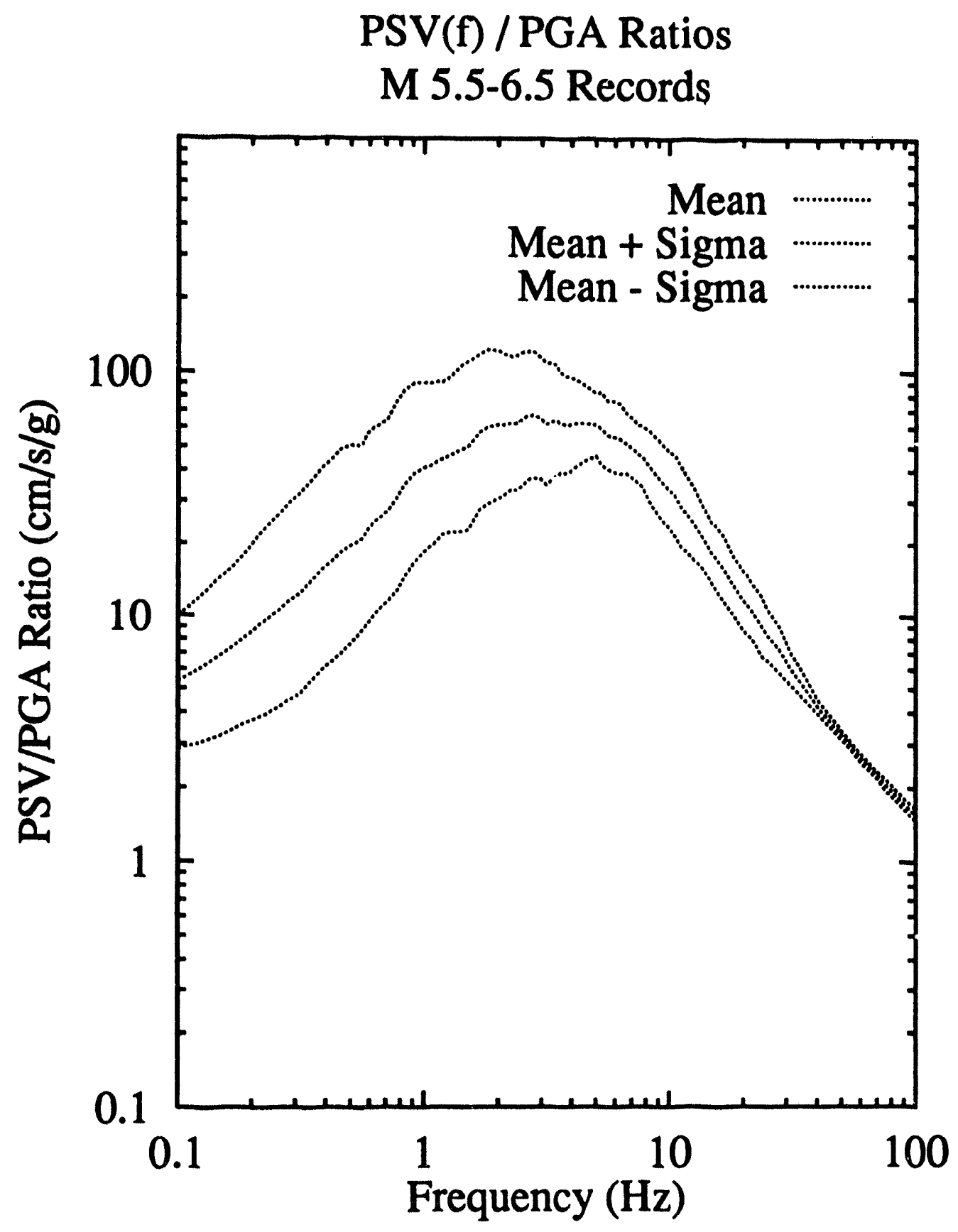

Figure 6 


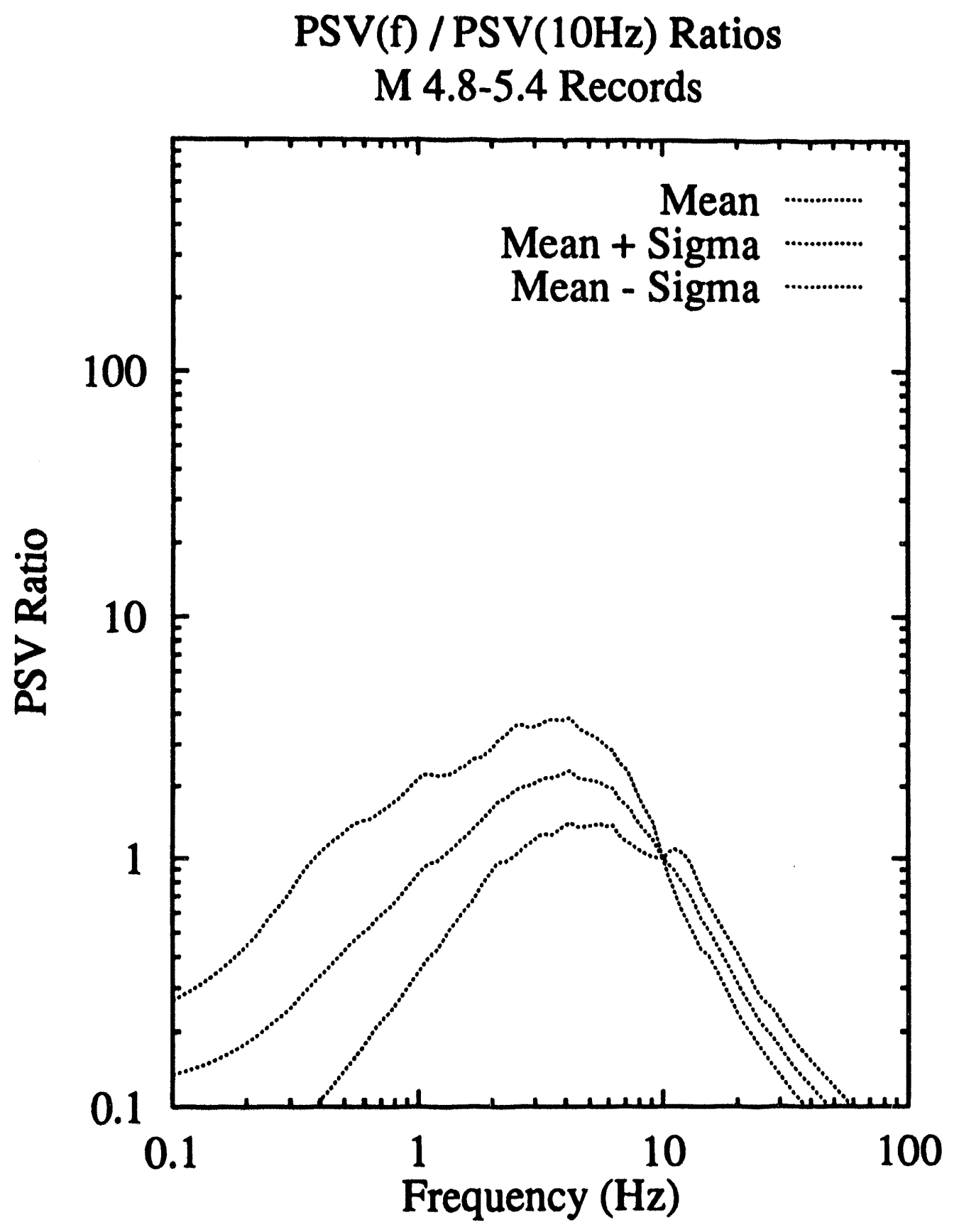

Figure 7 


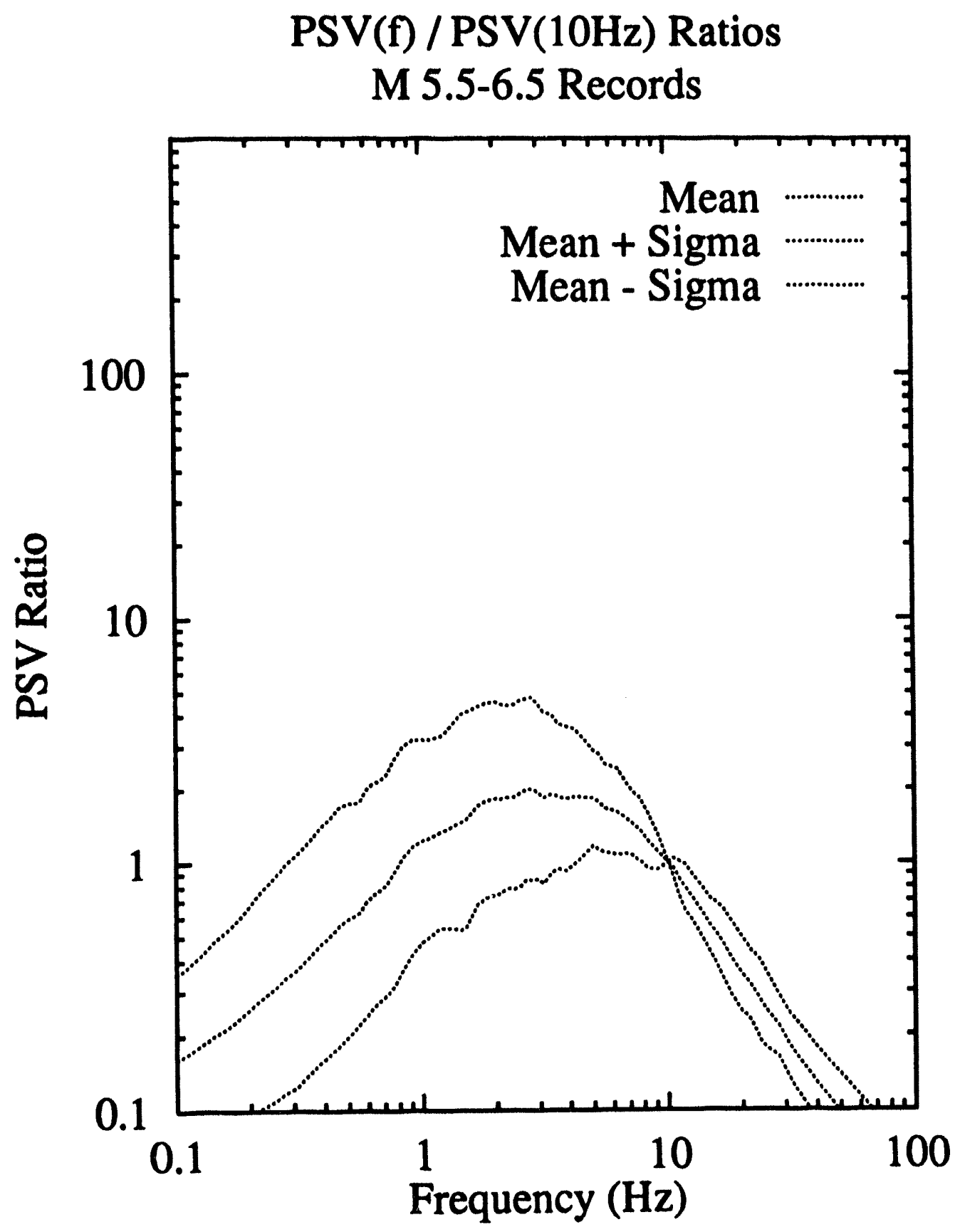

Figure 8 


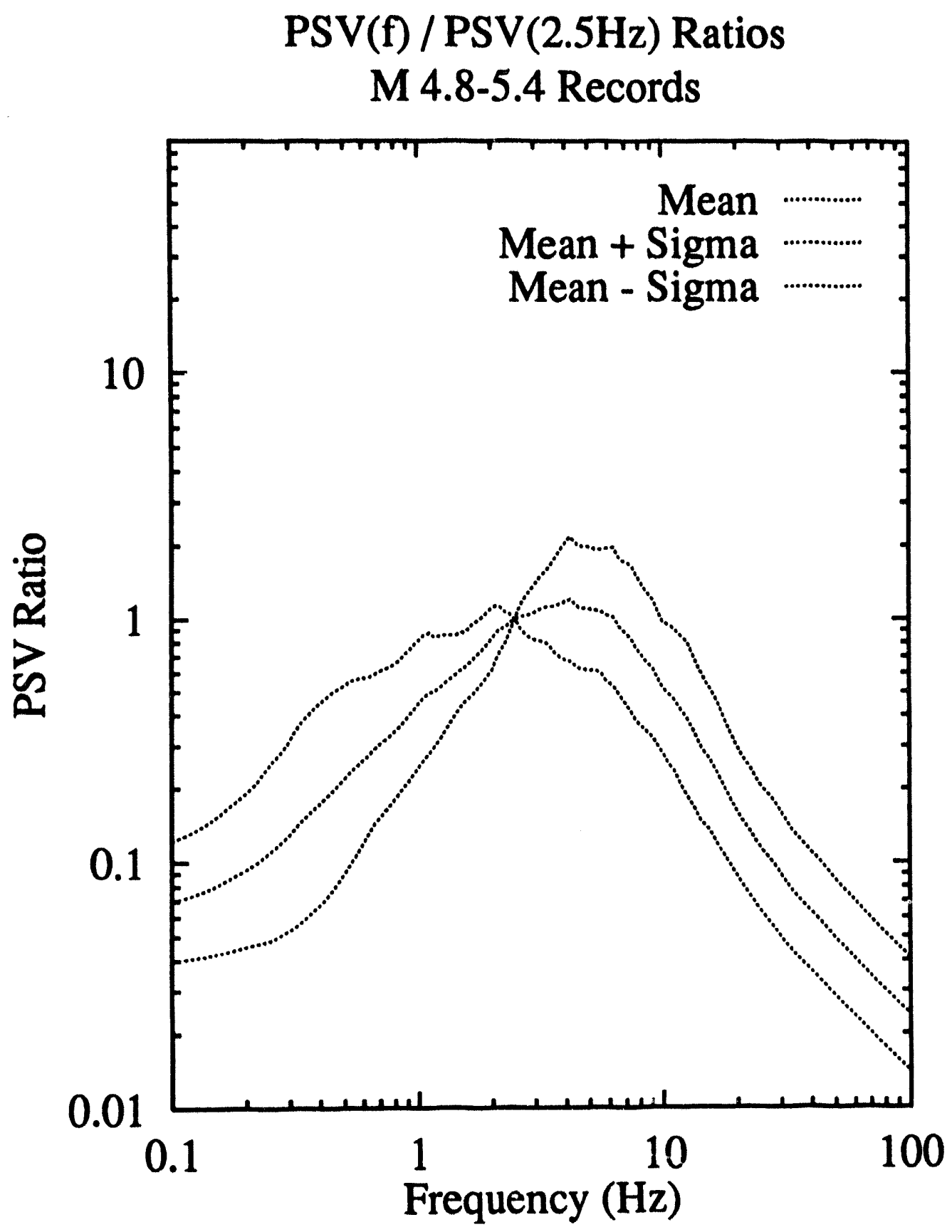

Figure 9 


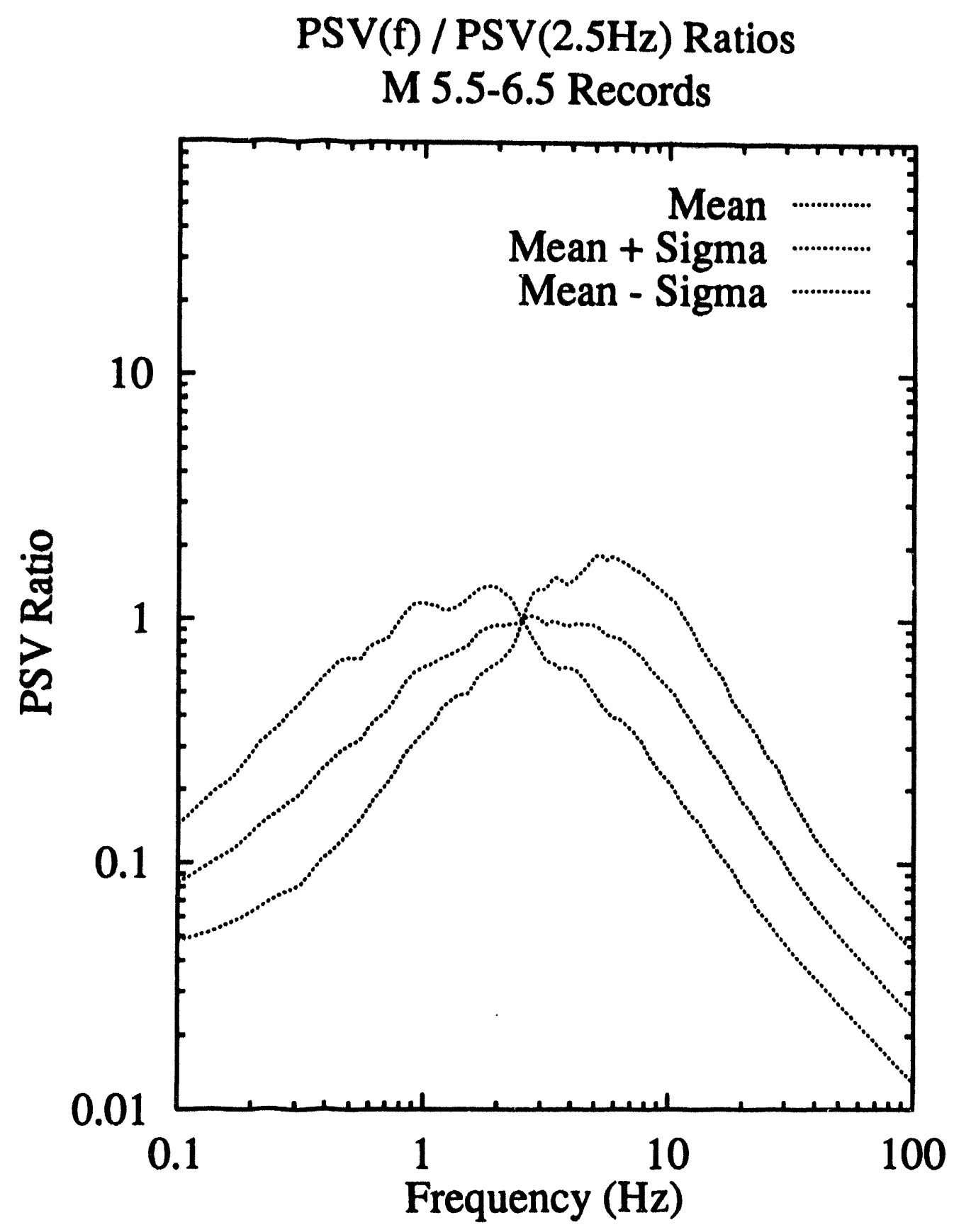

Figure 10 
Scaled Spectra from M 4.8-5.4 Records vs. Oak-Ridge Spectra

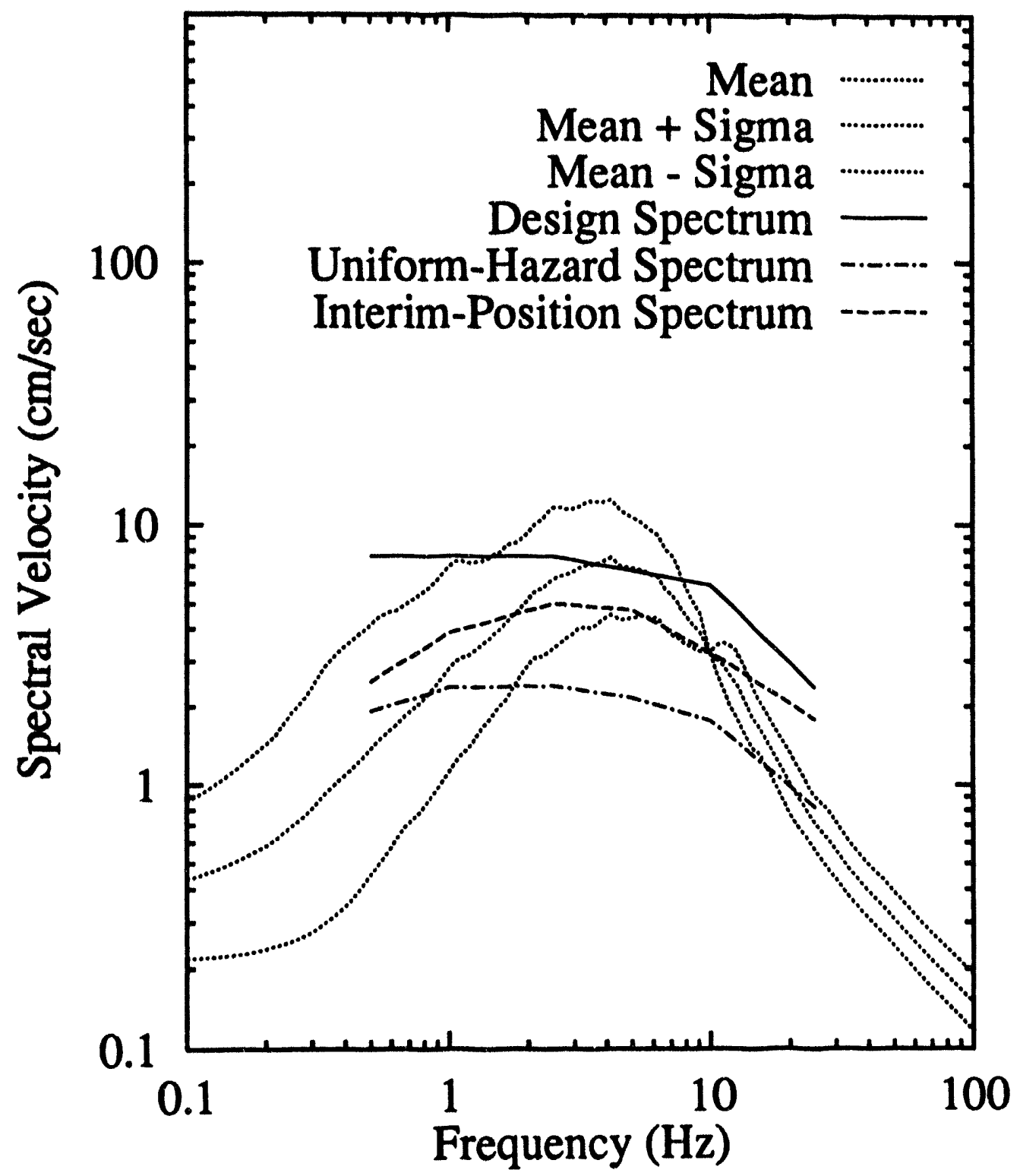

Figure 11 
Scaled Spectra from M 5.5-6.5 Records vs. Oak-Ridge Spectra

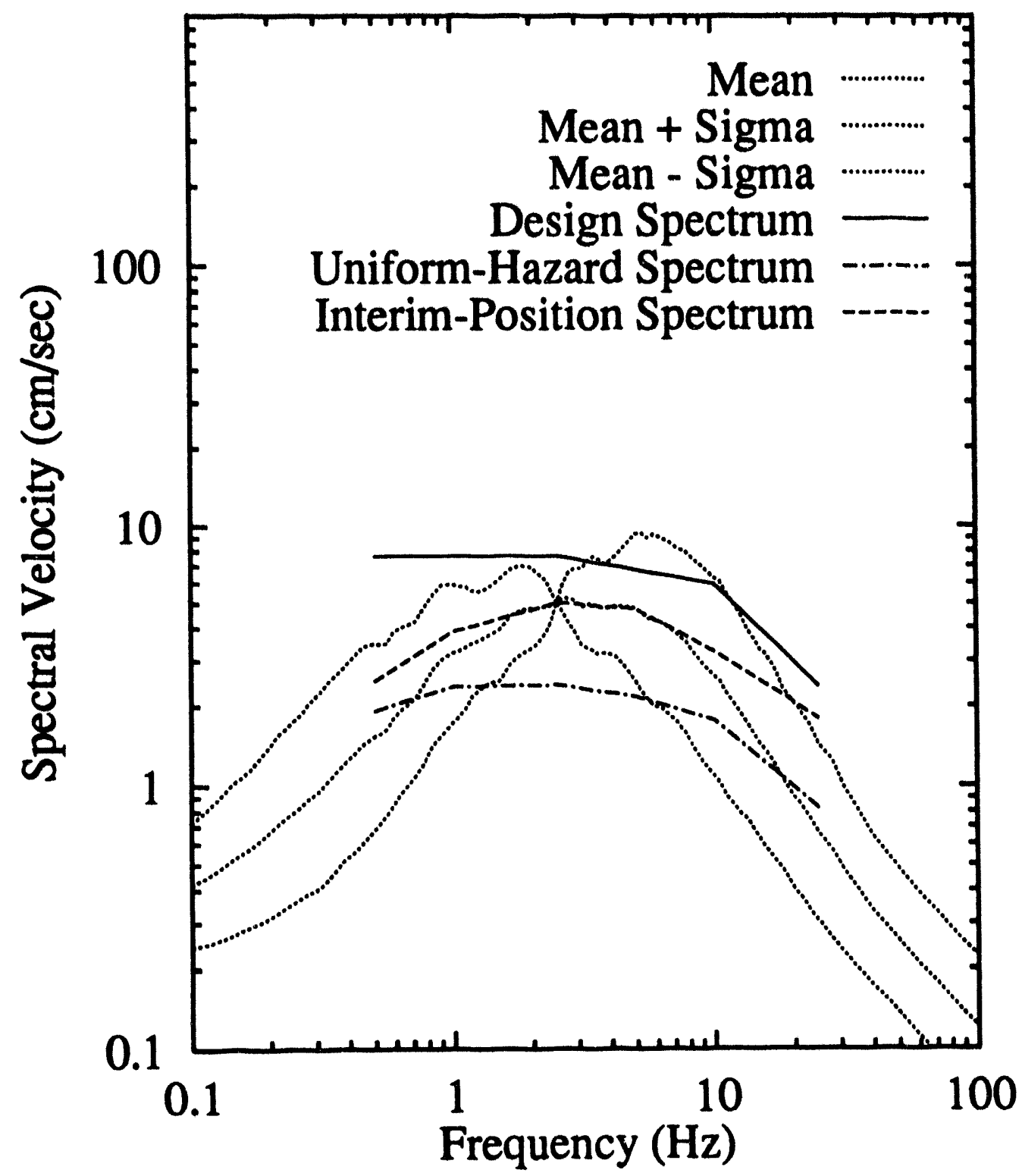

Figure 12 
Response Spectra Normalized to M 5.1, R $38 \mathrm{~km}$ vs. CEUS Attenuation Function

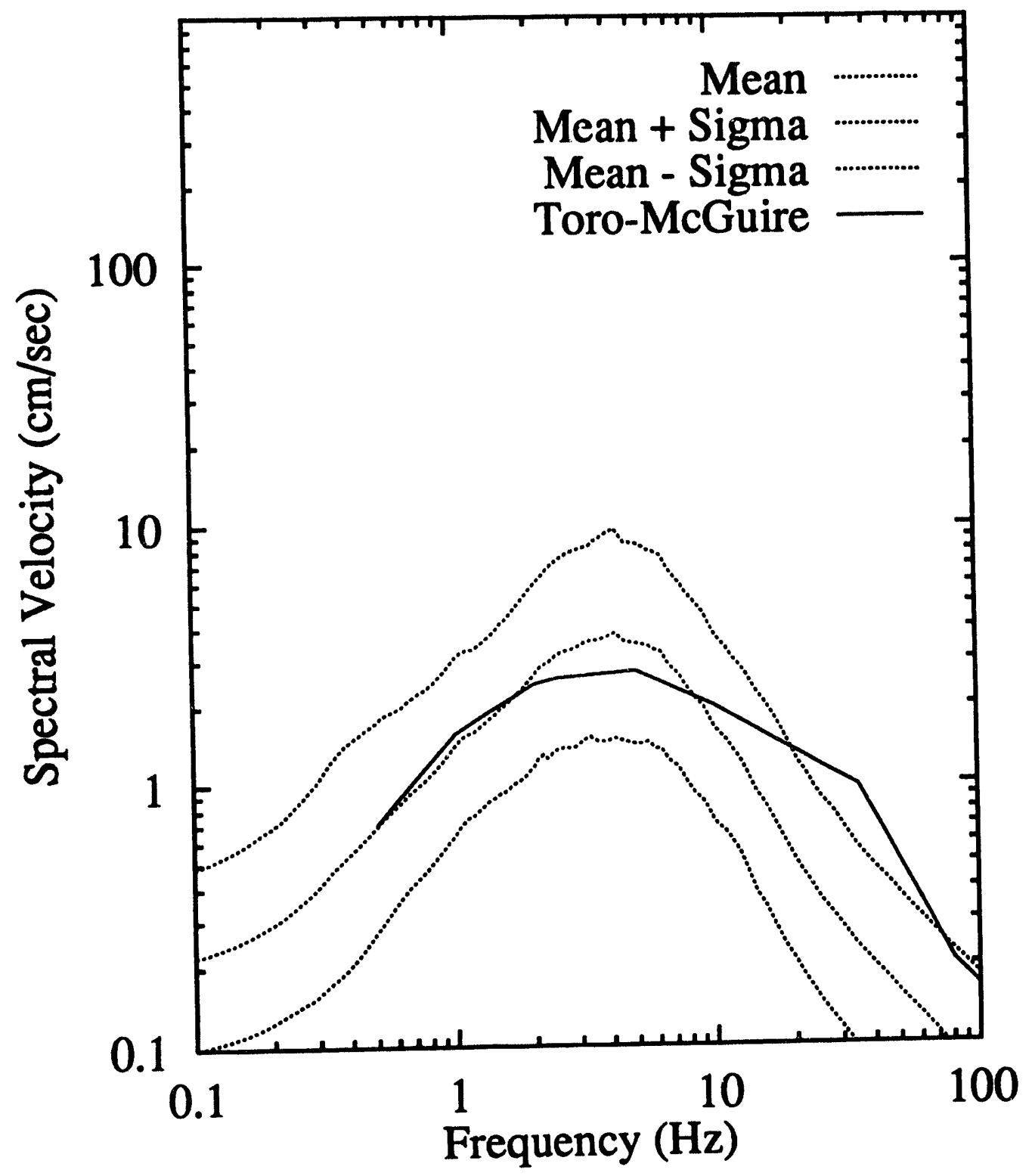

Figure 13 
Response Spectra Normalized to M 6, R $100 \mathrm{~km}$ vs. CEUS Attenuation Function

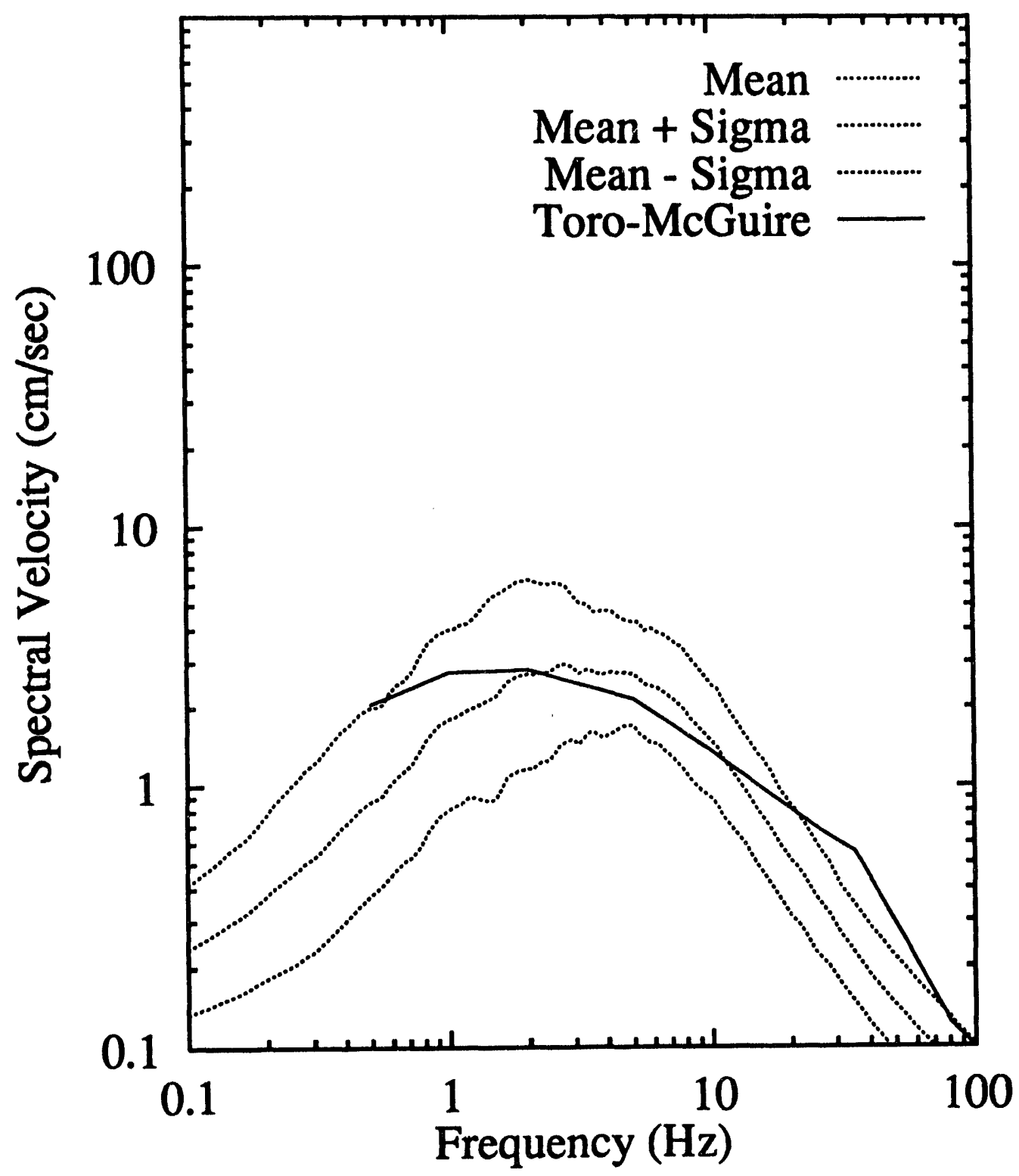

Figure 14 
Distribution:

J. E. Beavers

C. J. Constantino (City of New York)

D. R. Denton

R. J. Hunt

J. K. Kimball (DOE-HQ)

A. K. Le日 (DOE-OSTI - 2)

E. V. Leyendecker (U.S. Geological Survey

R. W. Rucker (DOE-ORO)

K. E. Shaffer

W. P. Staub

R. L Street (University of Kentucky)

D. W. Sykora (U.S. Army Engineer Waterways Experiment Station)

D. L. Wall (DOE-ORO)

W. L. Wicke

A. K. Zava

CNPE Library

Y-12 Central Files

Oak Ridge National Laboratory

ORNL Central Research Library

K-25 Library

K-25 Applied Technical Library 

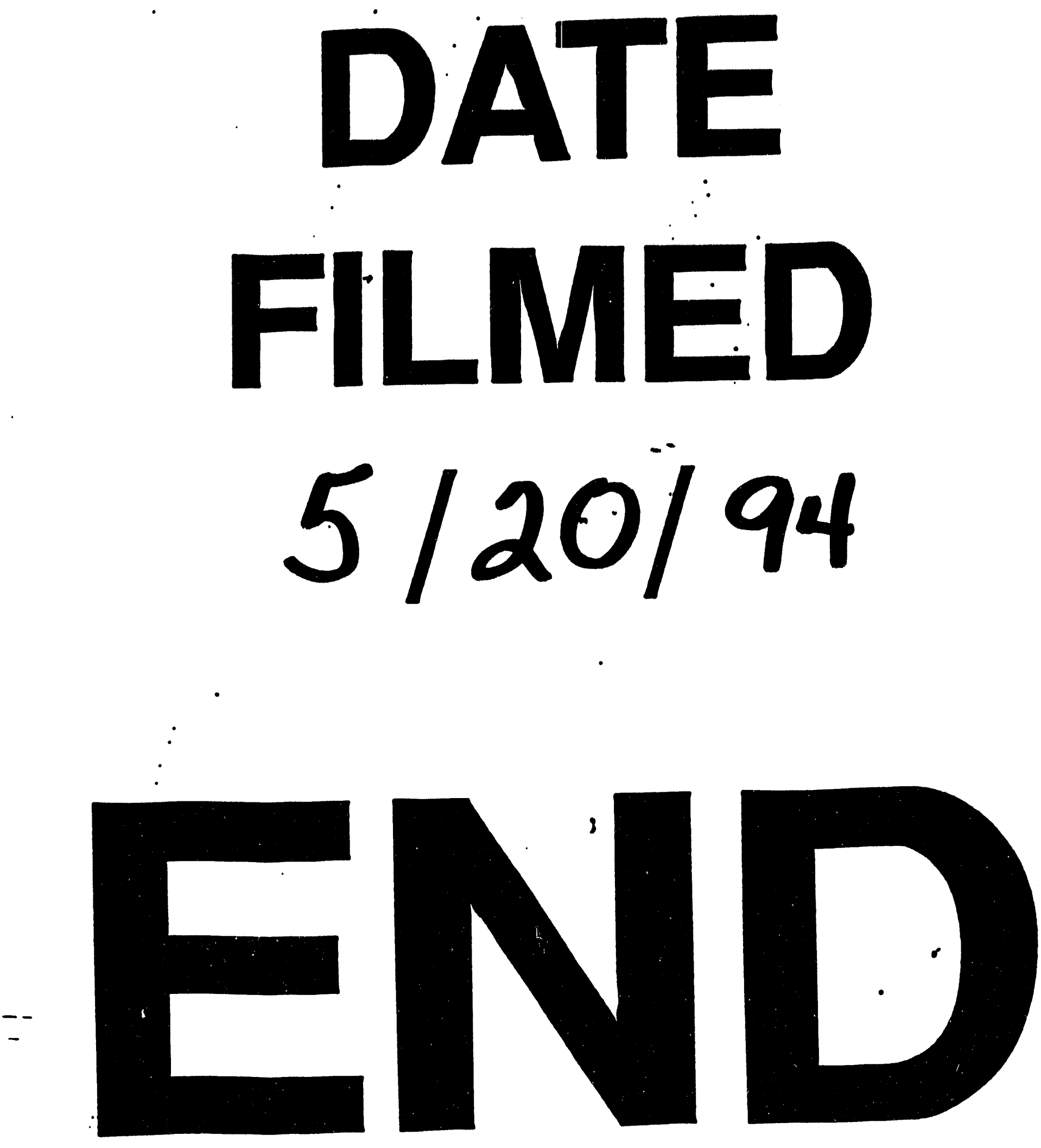
. 